\title{
Review and expert survey of allocation methods used in life cycle assessment of milk and beef
}

\author{
Venla Kyttä ${ }^{1}$ (D Marja Roitto ${ }^{1,2,3} \cdot$ Aleksi Astaptsev $^{4} \cdot$ Merja Saarinen $^{5} \cdot$ Hanna L. Tuomisto $^{1,3,5}$
}

Received: 20 April 2021 / Accepted: 15 December 2021 / Published online: 23 December 2021

(c) The Author(s) 2021

\begin{abstract}
Purpose Beef and dairy production systems produce several by-products, such as fertilizers, bioenergy, hides, and pet foods, among which the environmental impacts arising from production should be allocated. The choice of allocation method therefore inevitably affects the results of life cycle assessment (LCA) for milk and beef. The aims of this study were to map out the different allocation methods used in dairy and beef LCA studies and to clarify the rationale for selecting a certain method. Methods A literature review was conducted to identify the different allocation methods used in LCA studies of milk and beef production and the products using beef by-products as a raw material. The justifications for the use of different methods in the studies were also collected. To map out the perspectives of LCA practitioners and further clarify the reasoning behind the use of certain allocation methods, a mixed method survey with quantitative questions and qualitative explanatory fields was sent to the authors included in the literature review.

Results and discussion The literature review showed that the most commonly used allocation method between milk and meat was biophysical allocation, which is also the recommended method in LCA guidelines of milk production. Economic allocation was the second most common method, although the rationale for using economic allocation was weak. By-products, such as inedible body parts, were not considered in milk studies and were taken into account in only a small number of beef studies. This might be because most of the studies have cradle-to-farm gate system boundaries. According to the survey, a significantly higher share of LCA practitioners would allocate impacts also to these by-products.

Conclusions The allocation is usually done between milk and meat, and other by-products are not taken into account. Since these materials are an unavoidable part of production and there are numerous uses for them, these outputs should be recognized as products and also taken into consideration in LCA studies.
\end{abstract}

Keywords LCA $\cdot$ Allocation methods $\cdot$ System expansion $\cdot$ Integrated dairy-beef production $\cdot$ By-product

\section{Introduction}

Communicated by Arnaud Hélias

Venla Kyttä

venla.kytta@helsinki.fi

1 Future Sustainable Food Systems - research group, Department of Agricultural Sciences, Faculty of Agriculture and Forestry, University of Helsinki, Helsinki, Finland

2 Faculty of Agriculture and Forestry, Ruralia Institute, University of Helsinki, Helsinki, Finland

3 Helsinki Institute of Sustainability Science (HELSUS), University of Helsinki, Helsinki, Finland

4 Department of Bioproducts and Biosystems, School of Chemical Engineering, Aalto University, Espoo, Finland

5 Natural Resources Institute Finland, Helsinki, Finland
Environmental impacts of beef production have been investigated extensively using life cycle assessment (LCA) (Poore and Nemecek 2018). Studies have found the impacts of beef from dairy production to be notably lower than those of specialized meat production systems. As the edible parts of a bovine animal are only approximately $50 \%$ of the live weight, other materials, such as hides, bones, and body parts not suitable for food, are also generated (Mogensen et al. 2016). Most of these materials are utilized in, for example, garments, animal feeds, or biogas feedstock, thus could also be handled as by-products of the system with impacts being allocated to them (Gac et al. 2014; Mogensen et al. 2016). The environmental and climate crisis, and other sustainability problems, require the food system to adapt and change at the system level. Production processes and 
the use of raw materials are undergoing scrutiny, emphasizing the importance of by-products in the food system and thus also in the assessment of the life cycle environmental impact of (current) main products.

Even though the LCA method is in accordance with the International Organization for Standardization (ISO) (ISO 2006), the standard gives some freedom to decide how to implement the method for different products and processes, as long as the solutions are in line with the goal and scope of the study. Impact allocation between by-products is one decision that depends on the interpretation of the researcher performing the LCA. However, different allocation methods result in different allocation ratios between products, affecting the LCA results. ISO (2006) and ISO/TS 14,067 provide the following steps as a guideline for allocation in LCA (ISO 2013): (1) allocation should be avoided by creating sub-processes or applying a system expansion approach; (2) if allocation cannot be avoided, allocation should be based on the underlying physical relationships between products or functions; and (3) when physical allocation cannot be used, the allocation method should be based on another relationship between the products or functions (e.g., economic). When several allocation methods are applicable, sensitivity analysis should be performed to indicate the effect of methodological choices (ISO 2006). The standard leaves room not only for the choice of method but also for how a particular method is implemented. Hence, the term "system expansion" is sometimes used from two different perspectives: (1) assessing avoided burden/substitution and (2) expanding comparable systems by adding functions so that the systems include production of similar functions (Brander and Wylie 2011).

ISO standards are further specified by different institutions that have published guidelines concerning certain product groups. The International Dairy Federation (IDF) developed guidelines for attributional LCA, first launched in 2010 and updated in 2015 (IDF 2010, 2015). The recommendation for allocation between milk and meat is to use physical allocation, which is consistent with step 2 in the ISO 14044 standard. The allocation ratio is based on the formula presented by Thoma et al. (2013), which utilizes the mathematical relationship of feed energy converted to tissue or milk. In this approach, functions that are clearly associated with either product should be allocated accordingly (e.g., electricity used for milking) and the unassigned impacts at the farm gate allocated by the biophysical causality. Allocation ratio (AF) is calculated with the following formula:

$$
\begin{aligned}
\mathrm{AF} & =1-5.7717 \times \mathrm{R} \text { in IDF } 2010, \text { and } \mathrm{AF}_{\text {milk }} \\
& =1-6.04 \times \mathrm{BMR} \text { in IDF 2015, }
\end{aligned}
$$

where variables $\mathrm{R}$ and BMR have the same meaning, which is the ratio of meat and milk with meat being the live weight sum of animals sold and milk the sum of sold fat- and protein-corrected milk (FPCM). Thus, the formula given for calculating FPCM in the IDF guidelines is incorrectly the formula for energy-corrected milk (ECM) (Baldini et al. 2017). It is also noteworthy that the formula is based on US data, and therefore, might not be geographically, technologically, and temporally representative of other types of production systems (Rice et al. 2017; Nemecek and Thoma 2020). Based on typical values for BMR, IDF also gives (default) an allocation ratio of 0.856 to milk in IDF 2010 and 0.88 in IDF 2015. Biophysical allocation between milk and meat is recommended also in FAO's LEAP guidelines (FAO 2015) and the European Commission's Product Environmental Footprint Category Rules (PEFCR) for Dairy Products (EDA 2018). Another approach introduced by FAO is allocation based on protein content of products, which is applied after deducting other products and services (manure, draught power, capital functions) from the system (Opio et al. 2013).

Since the allocation takes place at farm gate between milk and live animal, the milk LCA guidelines do not take a stand on how impacts should be allocated between different parts of the animal. However, the FAO LEAP guidelines state that meat processing to edible and nonedible parts should be allocated first according to system separation based on product-specific activities and then based on 5-year average economic values of groups with different functions (e.g., edible parts, pet foods, hides, rendering products) (FAO 2015). The PEFCR for pet food and leather has also suggested allocating impacts to the slaughterhouse and rendering outputs according to economic value (De Rosa-Giglio et al. 2018; FEDIAF 2018).

The effects of using different allocation methods to partition impacts between milk and beef have been addressed in several studies previously (Cederberg and Stadig 2003; Flysjö et al. 2011; Kristensen et al. 2011; Nguyen et al. 2013; Weiler et al. 2014). The methods for handling other by-products, such as hides, bones, tallow, and manure, have received less attention, however, as have LCA practitioner's perspectives and arguments for using a certain method. The aims here were to explore the different allocation methods used in milk, beef meat, edible organs, and inedible by-product studies and to investigate LCA practitioners' rationale for using specific allocation methods.

\section{Materials and methods}

\subsection{Literature review}

The structured literature review was started by reviewing the included and excluded milk and beef environmental impact studies, both peer-reviewed and non-peer-reviewed, 
collected by Poore and Nemecek (2018). A further literature search in Google Scholar was conducted for milk on 2 March 2020 and for beef on 2 April 2020 to also include studies published after June 2016. The same search terms were used as in Poore and Nemecek (2018) for full text: "life cycle assessment" OR "life cycle analysis" OR "GHG emissions" AND the relevant product name ("milk" or "beef"). For milk the search terms "cow" AND "allocation" were also added to decrease the number of references from 12,900 to 1200 . Based on title and abstracts, 214 publications were assessed for compliance with the inclusion criteria (presented below), resulting in a total of 161 milk LCA studies included in this study. For beef, the search terms "meat" AND "allocation" were also added to decrease the number of references from 9790 to 1900. Based on title and abstracts, 134 full publications were assessed more closely, 21 of which met the inclusion criteria.

To inspect the allocation of impacts to different beef byproducts from another perspective, LCA studies of products using beef by-products as raw material (e.g., biodiesel, leather goods) were also searched. A search with the terms "life cycle assessment" OR "life cycle analysis" OR "GHG emissions" AND "allocation" AND "animal by-products" from the year 2000 to present day was conducted on 23 April 2020. As a result, 104 full publications were assessed more closely and 11 were included in this study.

A complementary search with the same search terms was conducted in Scopus on 13 August 2021. The search resulted in 25 milk studies, 11 beef studies, and 3 byproduct studies that met the inclusion criteria and were not found in the first search in Google Scholar, and thus, were included in this study.

The following inclusion criteria for studies were applied: published 2000 or thereafter, accessible, uses LCA method, reports an allocation method, calculates the product's carbon footprint, and reports results in numeric form per product output unit ( e.g., FPCM, live weight). Studies rejected for failing to meet the criterion "accessible" included mostly reports from organizations for which no full publications were found. The following information was collected from the studies: product being investigated, publication type, goal of the study, system boundary used in the study, functional unit, and allocation method used (presented in Supplementary material S1). The publications were classified into different publication types such as peer-reviewed journal articles, reports, conference papers, or other types of studies.

The goals of the studies were classified as follows: comparative studies (comparing different production systems or scenarios of the same product), comparative studies comparing different products (e.g., beef with other meats), studies quantifying the environmental impacts of a product (typically seeking hotspots), methodological studies developing, testing, or comparing methods or methodological approaches, consequential LCA studies, and studies that do not fit into any of the above categories. Based on this classification, we evaluated whether studies using a certain allocation method differ in their goals.

From studies reporting the allocation ratios used, all allocation methods and different allocation ratios were separated for individual observation (Supplementary material S1). The ratio was calculated for studies in which no allocation ratio was directly reported, but the results were presented as unallocated and allocated. It was unclear whether the ratio was calculated based on data from the study or using the default ratios ( 0.88 and 0.856$)$ presented by IDF in some milk studies applying biophysical allocation but not presenting the allocation ratio values used. These observations were excluded from the review.

To survey the argumentation behind selection of a certain allocation method and to detect possible repeating argumentations, the reasoning presented in studies using only one allocation method was collected and classified according to the given reasoning. The following categories were used: no reasoning presented, recommendation by ISO standard, recommendation by IDF, recommendation by PAS2050, comparison with another study using a certain method, the same method being used in another study or studies, considering the quality of the by-products, accounting for certain functions, consequential model, and accordance with the study goal.

\subsection{Survey}

To improve understanding of the perspectives of LCA practitioners and further clarify the reasoning behind the choice of certain allocation methods, a mixed method survey consisting of multiple-choice and open-ended questions was sent to the 192 authors included in the first literature search. The survey form is presented in Supplementary material S2. Quantitative data obtained from the survey were analyzed with MS Excel, and open-ended questions were grouped based on respondents' answers to the related multiple-choice questions. The representative reasonings behind choosing a certain reply are presented in the Results section together with the multiple-choice results. All survey replies are presented in Supplementary material S3. 
Table 1 Number of milk, beef, and by-product studies reporting the allocation method used. Several methods $=$ two or more methods used, No allocation $=$ study reported to allocate all impacts to one product, CLCA = consequential LCA model

\begin{tabular}{llll}
\hline Allocation method & Milk studies & Beef studies & $\begin{array}{l}\text { By-product } \\
\text { studies }\end{array}$ \\
\hline Biophysical & 60 & 8 & - \\
Economic & 49 & 13 & 5 \\
Several methods & 40 & 3 & 5 \\
Mass & 4 & 1 & 3 \\
Own method & 6 & 2 & 1 \\
System expansion & 6 & 1 & - \\
No allocation & 12 & 4 & - \\
Protein & 4 & - & - \\
CLCA & 2 & - & - \\
Energy & 2 & - & - \\
Fat and protein & 1 & - & - \\
\hline
\end{tabular}

\section{Results}

\subsection{Literature review}

A total of 186 milk, 32 beef, and 14 by-product studies reported the allocation method that they used (Table 1). Of these studies, most were peer-reviewed journal articles
(85\%), followed by reports (10\%), other type of studies $(3 \%)$, or conference papers $(2 \%)$.

The classification according to study goals showed that the share of different goals was similar regardless of allocation method, except that method research was more common in studies using several allocation methods and system expansion was more common in studies comparing different systems (Fig. 1). Biophysical allocation was not used in a single study aiming to compare different products.

In milk LCA studies, the biophysical allocation method was most commonly used, followed by economic allocation (Table 1). Contrary to the recommended ISO allocation steps, system expansion was used less often. In all these studies, system expansion was implemented as substitution with other sources of meat (beef from beef herd or pork), except in one study where it was unclear how the method was used. Aside from these, several other methods were used, including mass, protein, energy, and allocating all impacts to milk (Table 1).

Six authors also presented their own method comprising allocation of all impacts from birth to first lactation to meat and all emissions after that to milk (resulting in $84 \%$ allocated to milk), allocation based on the energy and protein requirements of the herd ( $88 \%$ ), allocation based on relation of milk production and live weight gain of herds (85\%), allocation based on farmers' assessment and valuation of the role of cattle in their livelihoods (60\%), allocation based on metabolizable energy
Fig. 1 Study goals when using a certain allocation method. Details concerning the classification are presented in the Materials and methods section. Methods that were used in less than five studies were excluded from the figure. $n=$ number of studies reported in Table 1

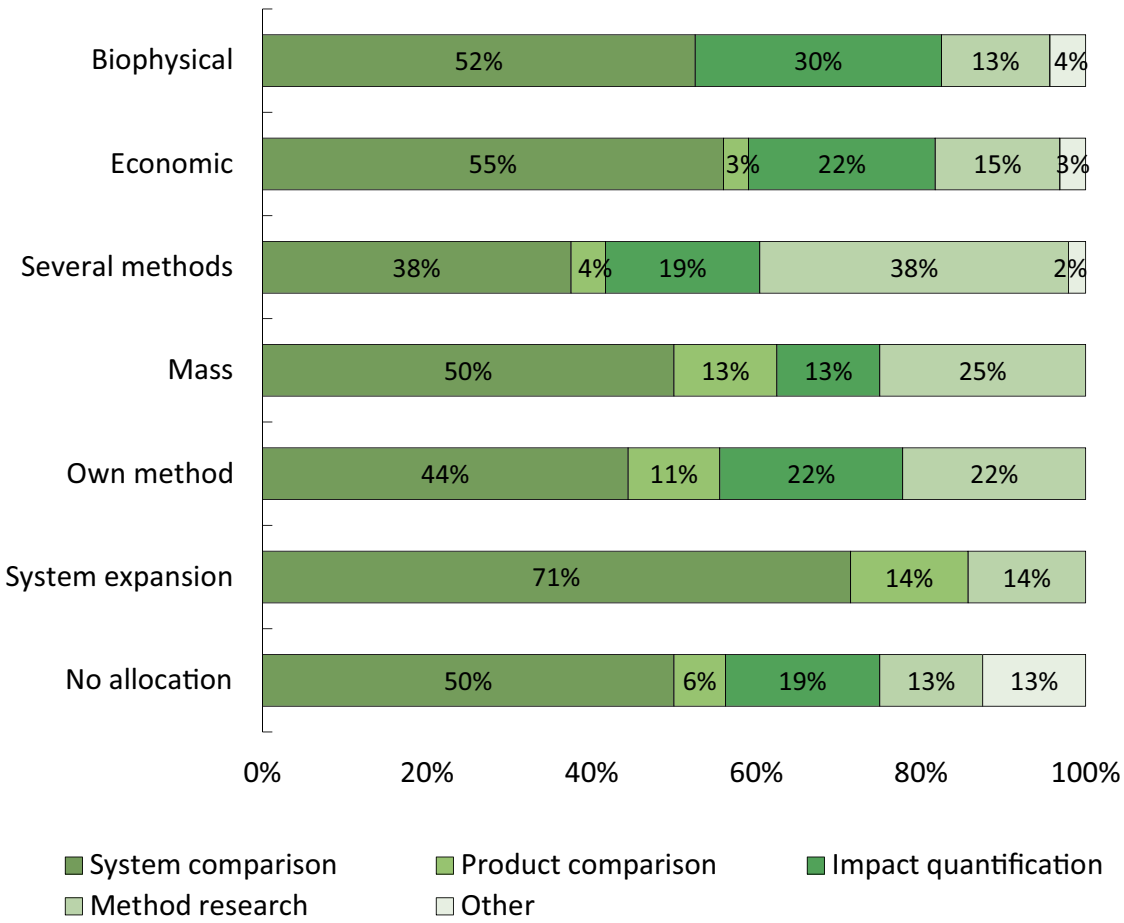


content (87\%), and allocation based on farmers' perception of the importance of different functions (49\%).

Despite the great number of beef carbon footprint studies published, only 32 of the studies covered by this review reported applying any allocation. The most commonly used method was economic allocation, followed by biophysical allocation (Table 1).

In LCA studies of products utilizing beef by-products, economic allocation was the most frequently used single method, but the use of several methods to test the impact of the methods was also common (Table 1).

\subsubsection{Allocation methods and their impact on results}

From studies reporting allocation methods, those also reporting allocation factors, consisting of 121 milk studies (349 observations), 15 beef studies ( 34 observations), and 12 by-product studies (21 observations), were further analyzed (Table 2).

The differences in allocation factors between allocation methods were notable, and allocation was applied mainly between milk and meat (Fig. 2). Nevertheless, in many studies, it was unclear whether allocation to meat referred to the whole animal (live weight) or only to actual meat since for instance in the IDF allocation formula "meat" stands for live weight. Manure was handled as a by-product in 18 studies. Most of these studies $(n=12)$ applied economic allocation and the rest $(n=6)$ used substitution. The average economic allocation ratio to manure (15 observations) was $4 \%$ and substitution $27 \%$ (9 observations). One study allocated impacts to hides and pet foods according to their economic value and two studies also included allocation to insurance value of stock on hand and financing value of animals to by-products.
In beef LCA studies, the allocation factors in different methods differed considerably (Fig. 3). Economic, energy, and mass allocation resulted in $87 \%, 80 \%$, and $73 \%$ of impacts being allocated to meat, whereas biophysical allocation resulted in only $27 \%$ being allocated to meat and the rest to by-products. One study applied its own allocation method by using economic allocation to hide and substitution to handle other by-products.

In LCA studies of products utilizing beef by-products, economic and mass allocation were the most used. Allocating according to energy content resulted in an even greater share of impacts (52\%) being assigned to by-products than to meat. Mass allocation also resulted in a relatively low share of impacts being allocated to meat (55\%), compared with economic allocation (88\% to meat) (Fig. 4). One study applied its own allocation method, which was the average ratio of mass, energy, and economic allocation.

\subsubsection{Rationale for the use of a certain method}

Most of the studies presented some argumentation to support the methodological choices concerning allocation between by-products. Authors applying several allocation methods, or an allocation method and consequential model, were aware of the effects of methodological choices and therefore decided to apply several methods.

The studies using only biophysical allocation method $(n=60)$ mostly justified the choice of method by either stating that it is recommended by IDF or that the approach is used by IDF ( $n=26$ ), and some studies also referred directly to the study by Thoma et al. (2013) underlying the IDF 2015 guidelines. Of the studies applying biophysical allocation,

Table 2 Number of included studies and allocation methods used in milk, beef, and by-product LCA studies. AR=allocation ratio, No allocation = study allocated all impacts to one product

\begin{tabular}{|c|c|c|c|c|c|c|}
\hline \multirow[t]{2}{*}{ Allocation method } & \multicolumn{2}{|l|}{ Milk studies } & \multicolumn{2}{|l|}{ Beef studies } & \multicolumn{2}{|c|}{ By-product studies } \\
\hline & $\begin{array}{l}\text { No. of studies } \\
\text { reporting AR }\end{array}$ & $\begin{array}{l}\text { No. of } \\
\text { observations }\end{array}$ & $\begin{array}{l}\text { No. of studies } \\
\text { reporting AR }\end{array}$ & $\begin{array}{l}\text { No. of } \\
\text { observations }\end{array}$ & $\begin{array}{l}\text { No. of studies } \\
\text { reporting AR }\end{array}$ & $\begin{array}{l}\text { No. of } \\
\text { observations }\end{array}$ \\
\hline Biophysical & 59 & 123 & 2 & 2 & - & - \\
\hline Economic & 58 & 116 & 11 & 16 & 7 & 7 \\
\hline Mass & 18 & 35 & 1 & 1 & 7 & 9 \\
\hline Protein & 12 & 23 & - & - & - & - \\
\hline Energy & 7 & 11 & 1 & 1 & 2 & 2 \\
\hline Emergy & 1 & 3 & - & - & - & - \\
\hline Nitrogen & 2 & 2 & - & - & - & - \\
\hline Fat and protein & 1 & 3 & - & - & - & - \\
\hline Fat & 1 & 1 & - & - & - & - \\
\hline System expansion ${ }^{a}$ & 5 & 7 & - & - & - & - \\
\hline Own method & 10 & 11 & 1 & 8 & 1 & 1 \\
\hline No allocation & 13 & 13 & 4 & 4 & 2 & 2 \\
\hline
\end{tabular}

${ }^{\mathrm{a}}$ Also includes substitution method 
Fig. 2 Allocation ratios (minmax-average) used in milk LCA studies by different methods as a ratio of total impact of the system allocated to milk. $n=$ observations reported in Table 2

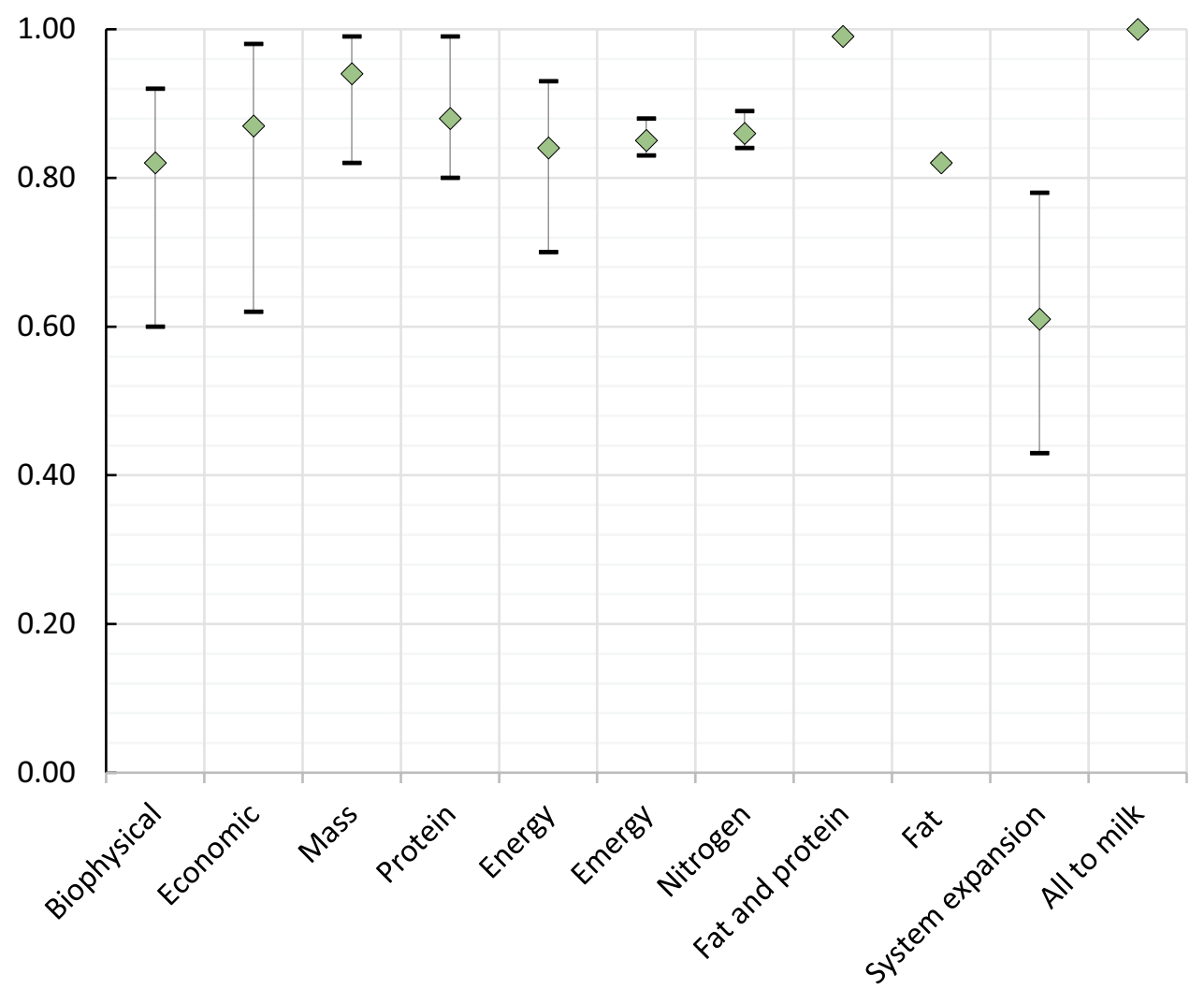

only four failed to present argumentation concerning their methodological choices.

Among studies applying only economic allocation ( $n=49)$, a large proportion $(n=9)$ presented no reasoning behind the methodological choice, and the most common argumentation $(n=11)$ was that the same method is used in another study or studies. Two studies referred to PAS2050 recommendations, one to EDEN tool, and three argued that economic allocation considers the variable quality of by-products.

Of the studies using only system expansion $(n=8)$, two were consequential LCA studies and the rest applied system expansion as a substitution method. Of these studies, only one referred to ISO standard allocation procedure and three to other studies. One study applied system expansion to account for multiple functions or enterprises on the farms, such as energy from biogas plant or non-feed plant production.

Of the studies using only mass allocation $(n=4)$, none presented the reasoning behind the allocation choices. Of the studies using only protein allocation $(n=4)$, two used the method since it reflects the primary function of the dairy sector as a provider of edible protein and two failed to provide reasoning.

Two studies used only allocation based on energy outputs without providing their rationale. In studies allocating all impacts to milk $(n=13)$, the most common reason $(n=5)$ was that this approach is consistent with the study goal or that the approach is also used in other studies $(n=4)$.

One study used nitrogen allocation, presenting as reasoning that nitrogen input is the most important factor determining the level of $\mathrm{N}_{2} \mathrm{O}$ emissions (Weiss and Leip 2012). Only one study used fat and protein contentbased allocation since nutritional content-based allocation methods are also used in other milk LCA studies.

\subsection{Survey of LCA practitioners' reasons for choosing allocation methods}

The response rate of the survey was $9.4 \%$ with 18 responses. The results for each question are presented below.

\subsubsection{Q1: "In the context of milk and beef production systems, what are the strengths and weaknesses of different allocation methods?"}

Although dividing into sub-processes is the first recommended method in ISO allocation steps, this approach was not used in any of the publications included in this study. 
Fig. 3 Average allocation ratios used in beef (from beef herd) LCA studies by different methods. All by-products category represents the combined total allocated to all by-products, and subsequent categories represent a more detailed breakdown between by-products if more detailed data were available

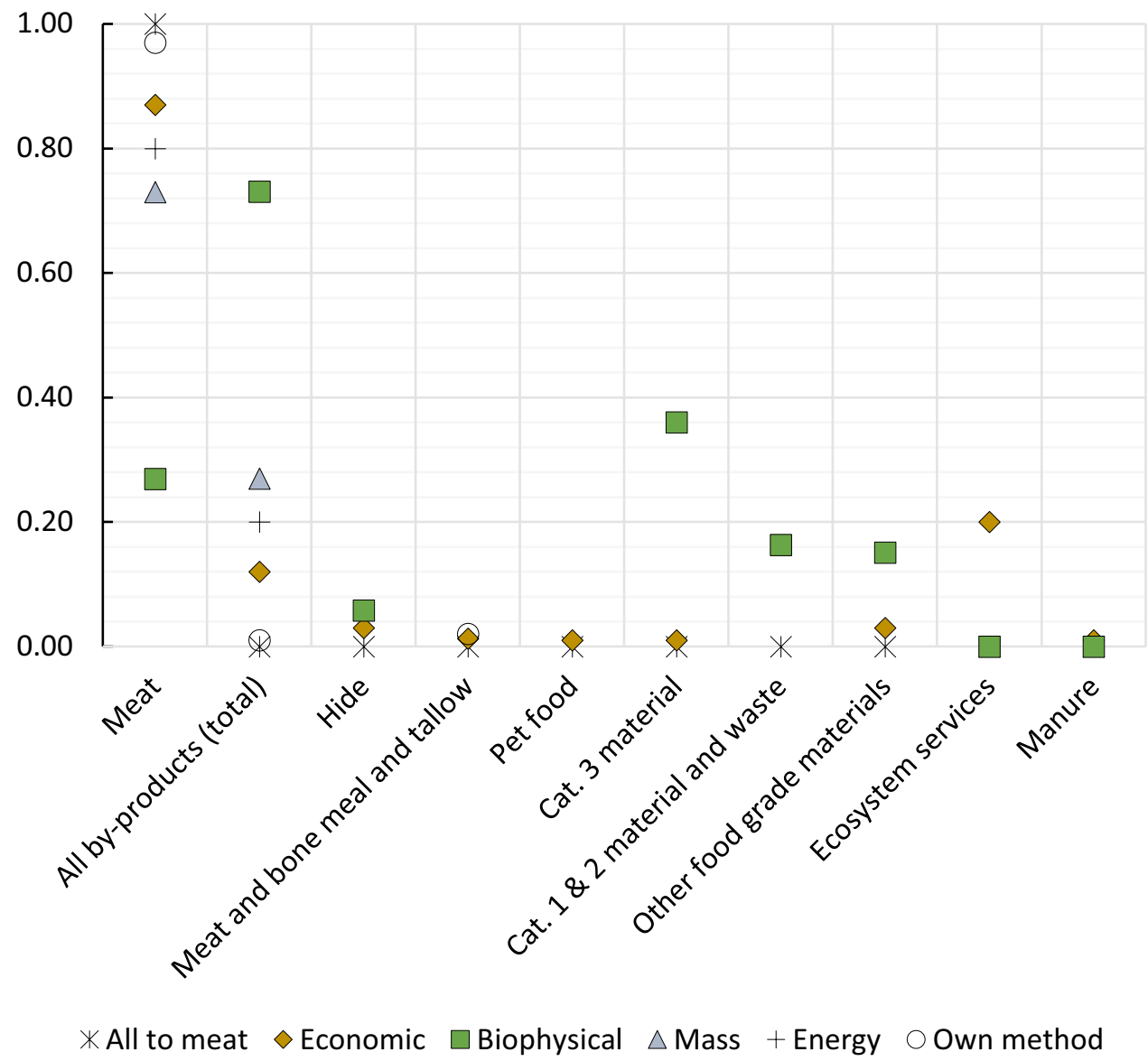

The survey respondents described this method as "the most accurate and logical" but also as "not possible to implement" in the context of animals. System expansion was also described as an "accurate" and "exact" method that "avoids arbitrary decisions about allocation factors," "takes into account the whole production process," and "contributes to the understanding of a more detailed scenario of the consequences that an action can cause." Weaknesses of the method cited included that it "is difficult to implement," "includes too many assumptions," "should not be used unless it is a full consequential model for the entire system," "limits use of results," "is often not relevant for research questions," and "lacks alternative systems."

The biophysical allocation method was the most commonly used method in milk LCA studies, and in the survey replies it was said to be "the easiest to implement and the most accurate according to IDF and PEF guidelines," "independent of most external factors," and "applicable and available." Weaknesses of the method were described as "difficult to quantify," "poor pedigree data for calculation," "difficult to explain to people outside the field," and "does not necessarily agree with value of the products." Rarer responses were "difficult to find the causality involved" and "there is no biophysical causality in milk production."

Economic allocation is also widely used, but the literature review showed that studies usually presented no rationale for the choice of method. In the survey, researchers described economic allocation as "easy to use and easily understood," "reflecting the value driving the production system," which "can provide a good relative assessment of the importance of a product or by-product." It was also seen as a "standard method in LCA that provides results comparable with other studies." The weaknesses were listed as "too variable over time"; "may not represent true value to society"; "prices do not reflect local conditions, values, and demands (e.g., local milk price depends on global auction pricing, not local economy)"; "the allocation factor changes depending on which person buys the product, for instance, whey as fodder or whey for human nutrition"; and "not all functions of livestock systems have a market value."

Allocation based on mass was seen as an "easy" method, but otherwise, it was described as "not relevant," "meaningless," or "cannot think of any case where this would be a reasonable representation." Dry mass allocation was also said to be "easy" and a method that "avoids major errors that 
Fig. 4 Average allocation ratios used in LCA studies of products utilizing beef by-products as raw material. Meat includes also other edible parts. All by-products category represents the combined total allocated to all by-products, and subsequent categories represent a more detailed breakdown between byproducts if more detailed data were available

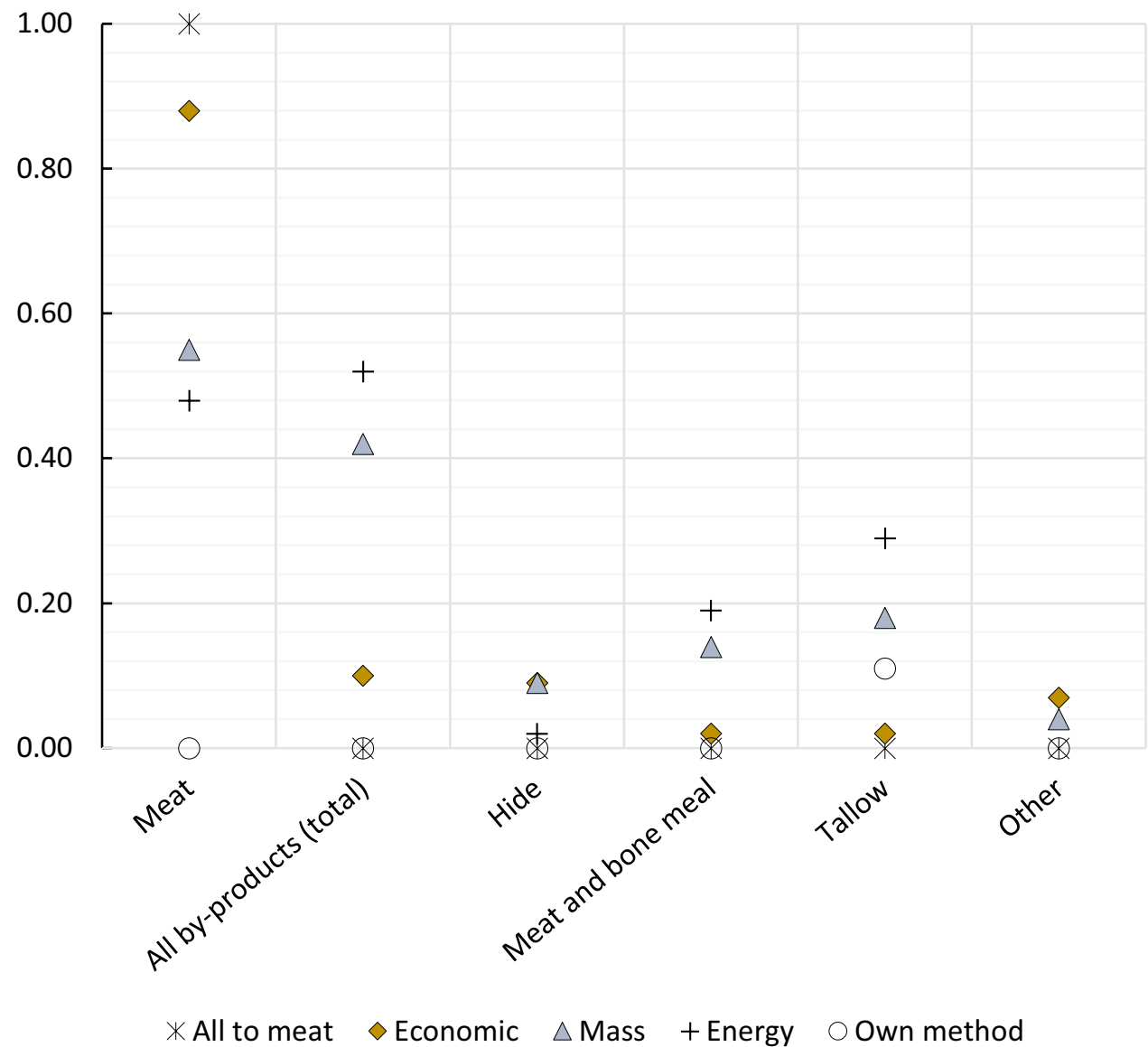

can be introduced through economic allocation." The weaknesses of the method were "not easy to collect data on dry mass," "not the best representation of the true value of each (product)," "lots of bias," "quality or value not considered," "not relevant," and "meaningless."

The strengths of protein allocation were described as "useful for comparison with other food," "quite easy," "reflects an important aspect of milk composition and a positive aspect of health," and "relevant for food." Listed weaknesses were that it "does not fully represent food value," "it is economically important but may not reflect a holistic view of the system," it is "arbitrary," and difficult to implement due to "lack of data." It was also argued that "milk and meat have nutritional value besides protein" and, for example, "whey is a product that has much protein but is a by-product that cannot always be sold at suitable prices and is partly used as fodder." Protein allocation was also stated to have "no particular weakness; the use of this allocation method should be related to the functional unit used and to the purpose of the study. Protein content does not reflect the reality of why milk is processed."

Strengths of energy allocation were described as "useful for comparison with other food," "sound mechanistic basis," "simple," "precise," and "environmental adherence."
Weaknesses were similar to those of protein allocation, e.g., "does not consider quality or value," "protein represents only one part of the system," "arbitrary," "lack of data," and "milk and meat have nutritional value besides protein."

\subsubsection{Q2: "Which allocation method would you use for allocating impacts between milk and living animals?"}

Most respondents would use biophysical allocation between milk and live animals since it is "the easiest to implement and the most accurate according to IDF and PEF guidelines" and "less context-dependent and takes into account the requirement difference between milk and meat" (Fig. 5).

The second most frequently selected method was economic allocation since "it is the simplest and most accurate method" that "reflects the economic reality that drives the production system," "best reflects input to system or output of system," and is "used in most LCA studies of livestock products." However, "it assumes that production is marketoriented, and thus, it is not the best method for smallholder systems with production aimed at self-sufficiency." 


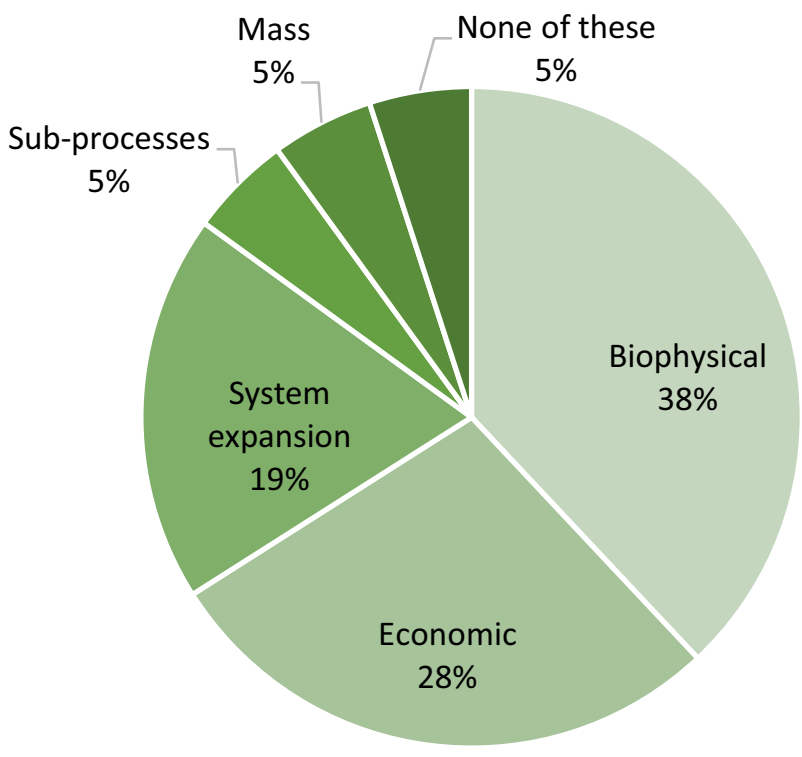

Fig. 5 Share of different methods that respondents would use to allocate impacts between milk and the living animal

Of the respondents, $19 \%$ would use system expansion "because in milk production we have several by-products with a value higher than whole milk."

Dividing into sub-processes "where the data exist to be able to use this method, it is the most appropriate and exact," and mass "proportions of raw material and products/derivatives well documented in the literature" were also selected. In addition, "none of the methods" was selected since "this question is impossible to answer as it depends on the goal of the specific study. No universal LCA rule exists for this problem as it depends on the stakeholders, reason, and intended application."

\subsubsection{Q3: How the following system outputs should be handled in LCA; as products, residues, or waste?}

(Product $=$ any good or service burdened with impacts, Residue $=$ any material output without burdens allocated to it, Waste $=$ substances or objects which the holder intends or is required to dispose of, impacts from disposal are allocated between products.)

Milk and meat were categorized as products since they are the "primary desired product" and have "high commercial value." Meat was also said to be "usually one of the things that the system exists to produce. If it is not a primary product (e.g., dairy system), it still has a food function." Manure was categorized as product, residue, and waste, but almost all explanations stated that the allocation to manure "depends on the system - would be a waste in a high input system and a product in a circular system at lower intensity" and how the manure is used "in the systems I model, manure is $100 \%$ returned to land (a legal requirement) so I have never had to build a model in which manure is an output; it normally lies within the system boundary" (Fig. 6).

Hides, bones, and tallow were mostly seen as a "valuable by-product" with economic value, but also as residue or waste. At the same time, internal organs or blood were seen more as residue, e.g., "useful by-product," or as a waste, e.g., "I do not know if they have any other industrial use."

\subsubsection{Q4:“If you would apply allocation in the following cases, which methods would you use and at what point of life cycle would the allocation take place?" For example which economic values and at what point (e.g., farm or slaughterhouse gate)"}

Case 1: Between milk and body parts (including meat)?

Most respondents would apply economic or biophysical allocation. All replied that the allocation should take place at the farm gate and one specified "at the farm gate, for body parts at the slaughterhouse" (Fig. 7).

Case 2: Between meat and different body parts (e.g., organs, bones, blood)?

The majority of respondents would use economic allocation to divide impacts between meat and the rest of the body parts. Mass was also cited relatively often considering that in previous questions, the view of mass allocation was rather negative. All replied that the allocation should take place at the slaughterhouse (Fig. 8).

\section{Case 3: Allocation to manure?}

Most would not allocate any impacts to manure or alternatively would use economic value, in case it exists. Some would also use system expansion to calculate credits from avoided fertilizer production. One reply stated "biophysical using LEAP Nutrient cycling guidelines." All replied that the allocation would take place at the farm gate (Fig. 9).

\section{Discussion}

This study supported the widely recognized problematic nature of by-product allocation methods. This methodological decision has an impact on the results, which has also been established in earlier studies (Flysjö et al. 2011; Kristensen et al. 2011). The review showed large variations in allocation 
Fig. 6 Share of replies concerning how to categorize different dairy system outputs. Product $=$ any good or service burdened with impacts, Residue $=$ any material output without burdens allocated to it, Waste $=$ substances or objects that the holder intends or is required to dispose of; impacts from disposal are allocated between products

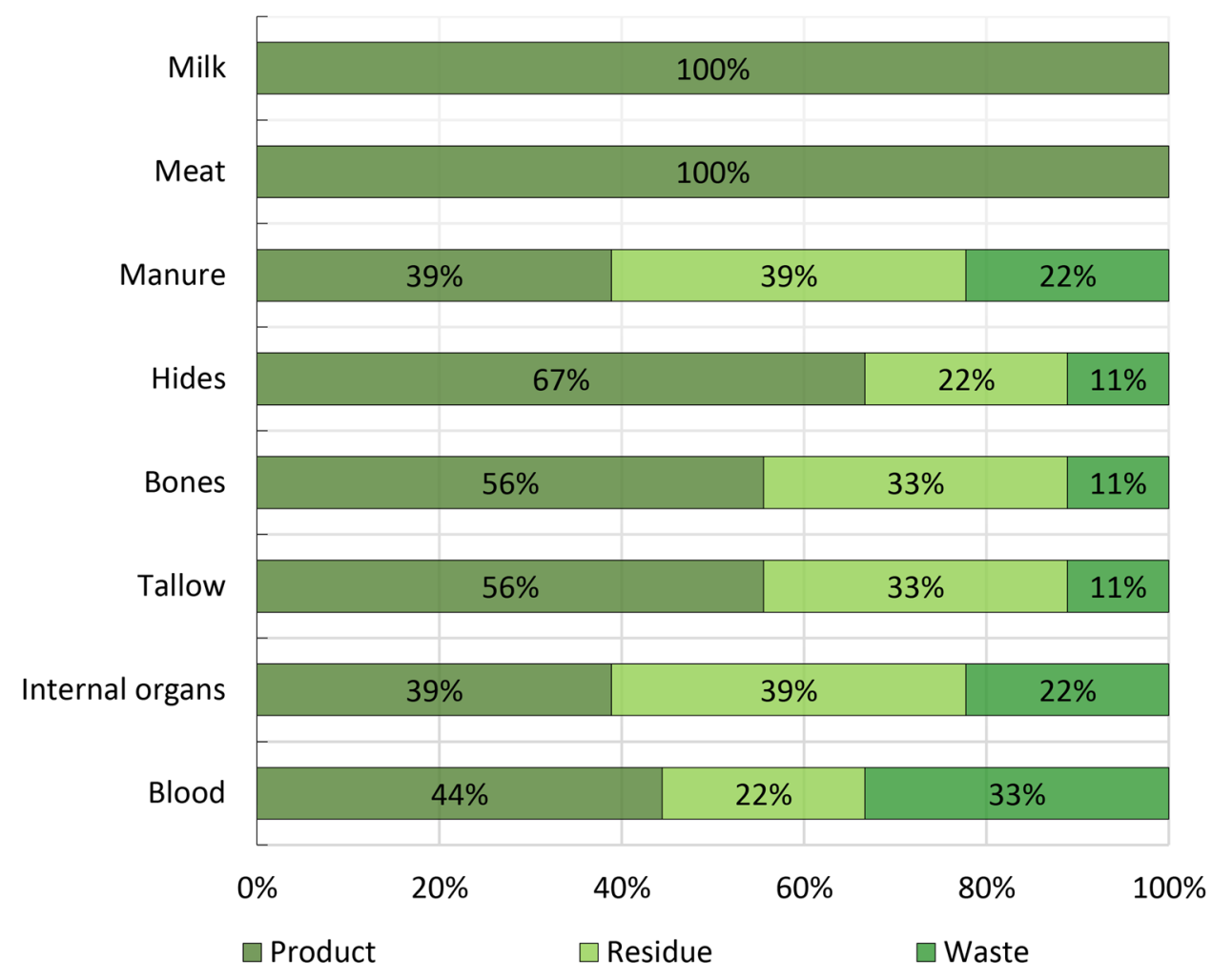

methods. Biophysical allocation and economic allocation were shown to be the most commonly used methods in LCAs of milk and beef, whereas protein, mass, energy, and system expansion are mainly used in studies comparing different

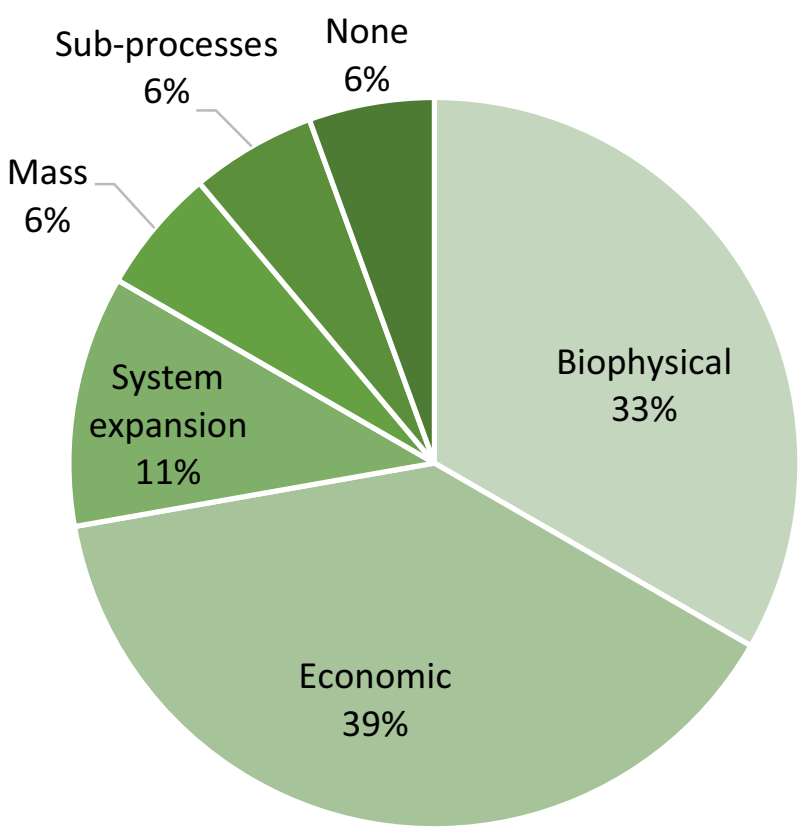

Fig. 7 Share of different allocation methods according to which LCA practitioners would allocate impacts between milk and body parts methods or in sensitivity analyses of studies to indicate the impact of an allocation method. Only a few studies included inedible products and allocated impacts to them. Some studies also reported allocating all impacts to one product since

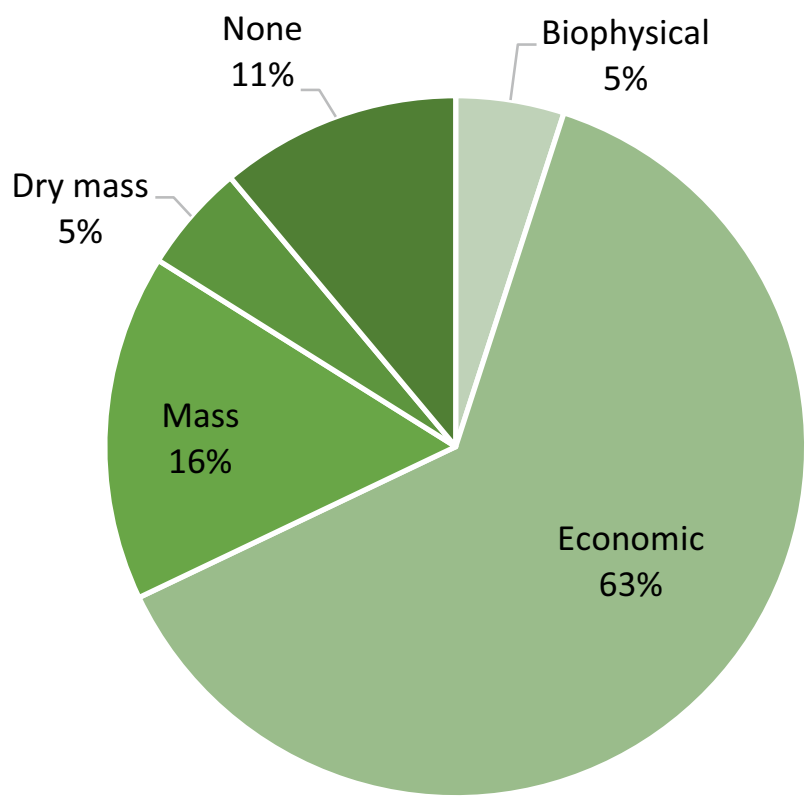

Fig. 8 Share of different allocation methods according to which LCA practitioners would allocate impacts between meat and different body parts 


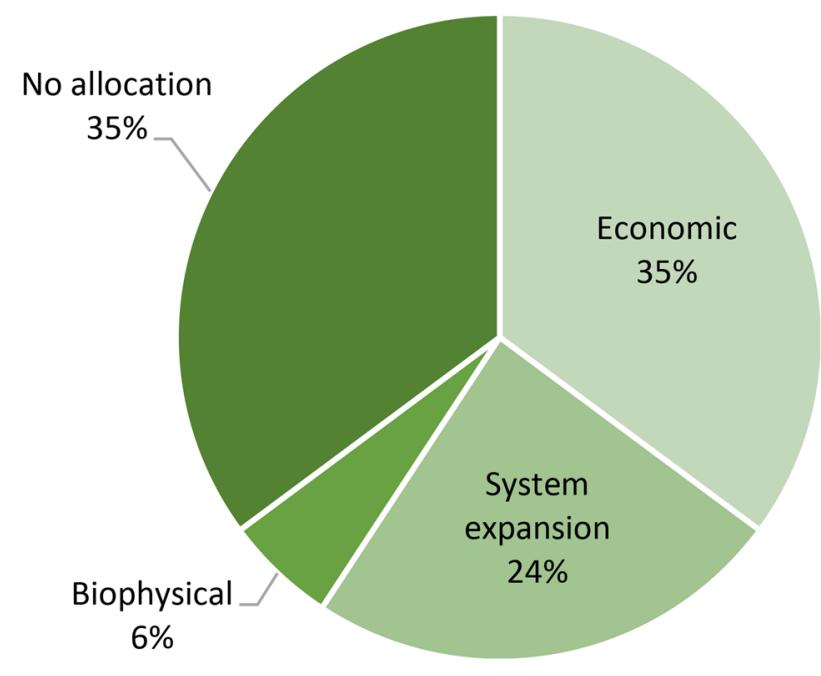

Fig. 9 Share of different allocation methods according to which LCA practitioners would allocate impacts to manure

allocation has no relevance for the study goal (e.g., comparing impact of mitigation practices). Thus, it should be noted that despite attempts to harmonize the method, allocation decisions should be in accordance with the study goal, and therefore, one method may not be suitable for all purposes.

\subsection{Allocation between different outputs}

In milk LCA studies, the allocation is mainly done between milk and meat, and other by-products, such as manure, hides, bones, and inner organs, are not taken into account. Only a few beef LCA studies included allocation to by-products. This might be due to most of the milk and beef studies having cradle-to-farm gate system boundaries, and therefore, the allocation is done only between the products that are sold from the farm (Baldini et al. 2017). Allocation should take place at the point where the products separate, but it should be discussed whether the allocation to different body parts could also take place at the farm gate in studies with a farm gate system boundary. Although body parts are not separated, they are still undeniably produced by the system and are one of the outputs of the system. This approach would also simplify problems arising from the use of different methods at different stages. For example, applying protein allocation at the farm gate and economic allocation at the slaughterhouse favors meat, but applying allocation at the same point allows allocation to by-products first, after which the impacts can be shared between meat and milk.

Provision of food and income for farmers was considered a general function of milk and beef production in the reviewed studies, but agricultural systems are also functioning ecosystems. Provisioning of food, fibers, and fuels is only one function of ecosystems, and other important benefits through supporting, regulating, and cultural services are also derived from ecosystems (MEA 2005). This kind of multifunctionality is generally not considered in LCA, but the few studies conducted on the topic show that the results obtained with inclusion of ecosystem services as outputs with impacts allocated to them differ greatly from the results of a standard LCA (Kiefer et al. 2015; Boone et al. 2019).

In addition to milk and meat, several other usable materials (e.g., inedible body parts and manure) are recovered from milk and beef production systems, even though they are usually not considered as products in the assessments. Still these materials are efficiently utilized, and a decrease in livestock production would also lead to a demand of alternative production of products derived from these materials. Efficient utilization of these by-products will be increasingly important when transitioning towards circular economy, and therefore, development of the methodology for handling these materials should also be advanced.

\subsection{Rationale for allocation methods}

Although being the most frequently used allocation method and recommended in the ISO standard as step 2, biophysical allocation, established particularly by IDF guidelines, has been criticized for favoring milk and not being applicable to extensive production systems, where the beef-to-milk ratio is high, since it results in a very low or even a negative allocation ratio for milk (Rice et al. 2017; Nemecek and Thoma 2020). The method also does not consider heifers sold to other dairy farms. Moreover, the confusion over ECM and FPCM formulae in IDF guidelines is not commonly recognized since it was not mentioned in the milk studies or in the survey, which increases the uncertainty of the milk LCA results. To avoid misunderstandings, reporting the entire formula used to calculate the functional unit in milk LCA studies is recommended (Baldini et al. 2017).

Another inaccuracy in the IDF formula is that it presents allocation between milk and meat, but the "meat" in fact includes the whole live weight of the animal. Thus, it is unclear whether the allocated result is meant for the whole animal or only the meat. To further allocate impacts of the whole animal, a biophysical allocation method for different body parts has been developed (Chen et al. 2017). However, this method leads to a relatively low share, around $50 \%$, of impacts being allocated to body parts used as human food. Since the method does not address the varying quality of the different by-products, it may overestimate the impacts of by-products in favor of edible parts. In addition, our study showed that biophysical allocation is not used in studies comparing different products, which might be due to a lack of established biophysical allocation procedures for other food products. 
Although biophysical allocation is based on physical causality, it usually uses economic value as a criterion to determine which output materials are considered as products with impacts allocated to them (Mackenzie et al. 2017). In this sense, the currently used biophysical allocation manner is not completely based on physical causality and detached from the socioeconomic context since materials classified as waste might vary depending on economic and cultural circumstances (Chen et al. 2017).

Economic allocation is widely used, even though biophysical allocation is the recommended method in milk LCA guidelines and also preferred over economic allocation in the ISO procedure. The literature review showed that the rationale for using economic allocation is weak, based usually only on the fact that it is used in other studies. In the reviewed studies and in the survey, subjects also mentioned that economic allocation makes the results more comparable with other studies since it is a widely used method. According to the survey, most of the LCA practitioners would still apply economic allocation between all products - milk, meat, manure, and non-edible body parts. Popularity of economic allocation may be due to its being simple to apply and illustrating properties of complex systems, also including differences in output material qualities (Ardente and Cellura 2012). Another reason to apply economic allocation is that it reflects the value to society or that the economy is the driving force of production. Instead of physical realism, economic allocation reflects the socioeconomic cause of impacts (Pelletier et al. 2015). However, Pelletier and Tyedmers (2011) argue that providing nutrition is the fundamental reason why food has economic value in the first place, and therefore, biophysical allocation approaches also cover socioeconomic functions of foods since they are based on physical properties of inputs and outputs.

Disadvantages of economic allocation are market fluctuations and context dependence, e.g., whether milk is produced in organic or conventional systems. The survey replies also revealed that prices depend on who the buyer is and the purpose of the product. Another weakness of economic allocation is that it easily indicates the cheapest byproducts as also being those with the lowest environmental impacts (Pelletier and Tyedmers 2011; Pelletier et al. 2015). Therefore, an increase in demand and consequently in prices would also lead to greater environmental impacts being allocated to by-products. This could lead to situations signaling that utilizing or recycling materials would be nonbeneficial from the environmental perspective. Thus, this kind of fluctuation only increases uncertainty since the demand of the by-product does not really affect the physical shares of the products derived from an animal.

Protein and energy allocations are related to the fundamental purpose of dairy and beef production as a food provider. Nevertheless, implementing these methods throughout the production chain requires data that may be difficult to obtain and the share of different amino acids and other nutrients in milk and meat also differ from each other (Rice et al. 2017). If methods used in LCA are nutrient contentbased, the approach should be more extensive to cover a variety of nutritional requirements (Saarinen et al. 2017). However, applying allocation based on nutritional properties might be challenging for nonfood products such as manure or inedible body parts.

In addition to allocation, the choice of functional unit as "quantified performance of a product system" also reflects the considered function of the system (ISO 2013). In this sense, a functional unit (e.g., certain amount of protein or energy) could also be seen as the first choice of allocation, as it defines the system functions to which the impacts are assigned. In addition, as suggested by one respondent in the survey, allocation and functional unit are also related and both should be selected in accordance with the goal and scope of the study. They should support each other. For example, recent efforts have been made to develop nutritional units that emphasize the nutritional importance of foods. In these cases, care should be taken that the environmental impact assessment of the product system does not use allocation solutions that distort the environmental impact of the feed streams on the products of the product system in terms of the nutritional properties presented in the functional unit. For example, economic allocation may do so because it reflects current economic relationships rather than causal relationships in the production chain. Instead, biophysical allocation could be a suitable allocation solution in this context, which emphasizes the importance of methodological solutions for the purpose and scope of the research, but the issue warrants further investigation.

Although system expansion is the first allocation step in the ISO standard allocation procedure, it is less frequently used and is usually included only for comparison of different allocation methods. In the studies, system expansion was implemented as substitution by assessing impacts from avoided production, which is in line with the interpretation made in early allocation studies (Brander and Wylie 2011). Substitution in attributional models has been suggested to favor milk production since all impacts from growing animals are fully allocated to beef, even though the animal is an unavoidable part of milk production (Rotz et al. 2010). The allocation factors found in this study also show the low share of impacts allocated to milk by system expansion (Fig. 2). Thus, system expansion is not implemented by including also functions of by-products. In this case, it would be impossible to obtain results for single products, which can conflict with the study goal.

The ISO standard does not differentiate consequential and attributional LCA. However, it has been proposed that attributional LCA only include actual burdens from the system and not those that do not physically occur (Brander and 
Wylie 2011). Since substitution method leads to a situation where credits are given when physical removals of emissions do not actually occur, it is possible to obtain negative LCA results even when emissions of a system are greater than removals occurring in the system (Brander and Wylie 2011). Thus, credits from avoided production (e.g., fertilizer substituted with manure) should not be given, although this approach is adapted in several studies (FAO 2015). The ILCD Handbook also states that it is incorrect to perform allocation to some by-products and substitution to others (European Commission 2010).

\subsection{Harmonization or compliance with study goals?}

As different allocation methods are suitable for different purposes, the method chosen should be congruent with the study goal. Efforts are made to harmonize the LCA method, but it should be noted that different objectives of the assessments also require adaptable methodology.

\section{Conclusions}

Dairy and beef production systems are multifunctional and produce several by-products, such as manure, hides, internal organs, and bones. These materials are an unavoidable part of production that have numerous uses as energy sources, fertilizers, pet foods, and raw materials for other industries. Demand for these materials is growing due to various circular economy solutions. Therefore, these outputs should be recognized as products and taken into consideration in LCA studies.

Most of the studies reported here had a farm gate system boundary, which is undeniably appropriate for studies that aim to compare different production practices. In applying this system boundary, it should be acknowledged that it is a whole animal leaving the farm, instead of meat, and product level results for meat can only be obtained by including the slaughtering stage in the study. The allocation guidelines also have some inaccuracies that make it difficult to know whether the impacts are allocated to meat or to the whole animal. Therefore, we recommend that milk and beef guidelines consider the slaughtering stage and provide the allocation method for different by-products. This would clarify the units used and the results obtained for both edible parts and by-products that are further processed. LCA practitioners should also clearly communicate the units used (e.g., instead of "milk," specify whether the unit is raw milk, ECM, or FPCM), the allocation method, and the share of impacts allocated to each product.

Furthermore, it should be clearly defined which outputs are considered as products in a specific study. The allocation method should be in accordance with the study goal and scope as well as the functional unit used, and consistently applied throughout the life cycle, if applicable.
Supplementary Information The online version contains supplementary material available at https://doi.org/10.1007/s11367-021-02019-4.

Author contributions VK: Methodology, Formal analysis, Investigation, Writing - Original Draft, Writing - Review \& Editing, Visualization MR: Conceptualization, Writing - Review \& Editing, Funding acquisition AA: Conceptualization, Writing - Review \& Editing MS: Writing - Review \& Editing HT: Conceptualization, Writing - Review \& Editing, Supervision, Funding acquisition.

Funding Open Access funding provided by University of Helsinki including Helsinki University Central Hospital. The authors received funding from the Ravitsemuksen Tutkimussäätiö and The Finnish Association of Academic Agronomists.

Data availability All relevant data are included in the article and/or its supplementary information files.

\section{Declarations}

Competing interest V. K., M. R., M. S., and H. T. have no relevant financial or non-financial interests to disclose. A.A. is employed by Valio Ltd.

Open Access This article is licensed under a Creative Commons Attribution 4.0 International License, which permits use, sharing, adaptation, distribution and reproduction in any medium or format, as long as you give appropriate credit to the original author(s) and the source, provide a link to the Creative Commons licence, and indicate if changes were made. The images or other third party material in this article are included in the article's Creative Commons licence, unless indicated otherwise in a credit line to the material. If material is not included in the article's Creative Commons licence and your intended use is not permitted by statutory regulation or exceeds the permitted use, you will need to obtain permission directly from the copyright holder. To view a copy of this licence, visit http://creativecommons.org/licenses/by/4.0/.

\section{References}

Ardente F, Cellura M (2012) Economic allocation in life cycle assessment. J Ind Ecol 16:387-398. https://doi.org/10.1111/j.1530-9290. 2011.00434.x

Baldini C, Gardoni D, Guarino M (2017) A critical review of the recent evolution of life cycle assessment applied to milk production. $\mathrm{J}$ Clean Prod. https://doi.org/10.1016/j.jclepro.2016.06.078

Boone L, Roldán-Ruiz I, Van linden V, Muylle H, Dewulf J (2019) Environmental sustainability of conventional and organic farming: accounting for ecosystem services in life cycle assessment. Sci Total Environ 695. https://doi.org/10.1016/j.scitotenv.2019. 133841

Brander M, Wylie C (2011) The use of substitution in attributional life cycle assessment. Greenh Gas Meas Manag 1:161-166. https:// doi.org/10.1080/20430779.2011.637670

Cederberg C, Stadig M (2003) System expansion and allocation in life cycle assessment of milk and beef production. Int J Life Cycle Assess 8:350-356. https://doi.org/10.1065/Ica2003.07.126

Chen X, Wilfart A, Puillet L, Aubin J (2017) A new method of biophysical allocation in LCA of livestock co-products: modeling metabolic energy requirements of body-tissue growth. Int J Life Cycle Assess 22:883-895. https://doi.org/10.1007/s11367-016-1201-y 
De Rosa-Giglio P, Fontanella A, Gonzalez-Quijano G, Ioannidis I, Nucci B, Brugnoli F (2018) Product environmental footprint category rules. Leather. https://ec.europa.eu/environment/eussd/ smgp/pdf/PEFCR_leather.pdf. Accessed 1 Jul 2020

EDA (2018) Product environmental footprint category rules for dairy products. https://ec.europa.eu/environment/eussd/smgp/pdf/ PEFCR-DairyProducts_2018-04-25_V1.pdf. Accessed 15 Jan 2020

European Commission (2010) Joint Research Centre. Institute for Environment and Sustainability. International Reference Life Cycle Data System (ILCD) Handbook - General guide for Life Cycle Assessment - Detailed guidance. https://doi.org/10.2788/38479

FAO (2015) Environmental performance of large ruminant supply chains: guidelines for assessment. Food and Agriculture Organization of the United Nations, Rome

FEDIAF (2018) Product Environmental Footprint Category Rules (PEFCRs) Prepared Pet Food for Cats and Dogs. https://ec.europa. eu/environment/eussd/smgp/pdf/PEFCR_PetFood_FinalPEFCRs_ 2018-05-09.pdf. Accessed 1 Jul 2020

Flysjö A, Cederberg C, Henriksson M, Ledgard S (2011) How does coproduct handling affect the carbon footprint of milk? Case study of milk production in New Zealand and Sweden. Int J Life Cycle Assess 16:420-430. https://doi.org/10.1007/s11367-011-0283-9

Gac A, Lapasin C, Laspière PT, Guardia S, Ponchant P, Chevillon P, Nassy G (2014) Co-products from meat processing: the allocation issue. In: Proceedings of the 9th International Conference on Life Cycle Assessment in the Agri-Food Sector (LCA Food 2014). San Francisco, USA. ACLCA, Vashon, WA, USA, pp 438-442

IDF (2010) A common carbon footprint approach for dairy The IDF guide to standard lifecycle assessment methodology for the dairy sector. Bulletin of the International Dairy Federation 445(2010):46. https://doi.org/10.1017/CBO9781107415324.004

IDF (2015) A common carbon footprint approach for the dairy sector: the IDF guide to standard life cycle assessment methodology 70. https://doi.org/10.1016/s0958-6946(97)88755-9

ISO (2006) ISO 14040:2006. Environmental management. Life cycle assessment. Principles and framework. International Organization for Standardization

ISO (2013) ISO/TS 14067. Greenhouse gases - carbon footprint of products - requirements and guidelines for quantification and communication. International Organization for Standardization

Kiefer LR, Menzel F, Bahrs E (2015) Integration of ecosystem services into the carbon footprint of milk of South German dairy farms. J Environ Manage 152:11-18. https://doi.org/10.1016/j.jenvman. 2015.01.017

Kristensen T, Mogensen L, Knudsen MT, Hermansen JE (2011) Effect of production system and farming strategy on greenhouse gas emissions from commercial dairy farms in a life cycle approach. Livest Sci 140:136-148. https://doi.org/10.1016/j.livsci.2011.03. 002

Mackenzie SG, Leinonen I, Kyriazakis I (2017) The need for coproduct allocation in the life cycle assessment of agricultural systems - is "biophysical" allocation progress? Int J Life Cycle Assess 22:128-137. https://doi.org/10.1007/s11367-016-1161-2

MEA (2005) Millenium ecosystem assessment 2005. Current State \& Trends Assessment
Mogensen L, Nguyen TLT, Madsen NT, Pontoppidan O, Preda T, Hermansen JE (2016) Environmental impact of beef sourced from different production systems - focus on the slaughtering stage: input and output. J Clean Prod 133:284-293. https://doi. org/10.1016/j.jclepro.2016.05.105

Nemecek T, Thoma G (2020) Allocation between milk and meat in dairy LCA: critical discussion of the International Dairy Federation's standard methodology. In: 12th International Conference on Life Cycle Assessment of Food LCA Food 2020, Berlin, Germany, 13-16 October 2020

Nguyen TTH, Doreau M, Corson MS, Eugène M, Delaby L, Chesneau G, Gallard Y, Van Der Werf HMG (2013) Effect of dairy production system, breed and co-product handling methods on environmental impacts at farm level. J Environ Manage 120:127-137. https://doi.org/10.1016/j.jenvman.2013.01.028

Opio C, Gerber P, Mottet A, Falcucci A, Tempio G, MacLeod M, Vellinga T, Henderson B, Steinfeld H (2013) Animal Production and Health Division - a global life cycle assessment. FAO, Rome

Pelletier N, Tyedmers P (2011) An ecological economic critique of the use of market information in life cycle assessment research. J Ind Ecol 15:342-354. https://doi.org/10.1111/j.1530-9290.2011. 00337. $\mathrm{x}$

Pelletier N, Ardente F, Brandão M, De Camillis C, Pennington D (2015) Rationales for and limitations of preferred solutions for multi-functionality problems in LCA: is increased consistency possible? Int J Life Cycle Assess 20:74-86. https://doi.org/10. 1007/s11367-014-0812-4

Poore J, Nemecek T (2018) Reducing food's environmental impacts through producers and consumers. Science 360(6392):987-992. https://doi.org/10.1126/science.aaq0216

Rice P, O'Brien D, Shalloo L, Holden NM (2017) Evaluation of allocation methods for calculation of carbon footprint of grass-based dairy production. J Environ Manage 202:311-319. https://doi.org/ 10.1016/J.JENVMAN.2017.06.071

Rotz CA, Montes F, Chianese DS (2010) The carbon footprint of dairy production systems through partial life cycle assessment. J Dairy Sci 93:1266-1282. https://doi.org/10.3168/jds.2009-2162

Saarinen M, Fogelholm M, Tahvonen R, Kurppa S (2017) Taking nutrition into account within the life cycle assessment of food products. J Clean Prod 149:828-844. https://doi.org/10.1016/j. jclepro.2017.02.062

Thoma G, Jolliet O, Wang Y (2013) A biophysical approach to allocation of life cycle environmental burdens for fluid milk supply chain analysis. Int Dairy J 31. https://doi.org/10.1016/j.idairyj. 2012.08.012

Weiler V, Udo HM, Viets T, Crane TA, De Boer IJ (2014) Handling multi-functionality of livestock in a life cycle assessment: the case of smallholder dairying in Kenya. Curr Opin Environ Sustain 8:29-38. https://doi.org/10.1016/j.cosust.2014.07.009

Weiss F, Leip A (2012) Greenhouse gas emissions from the EU livestock sector: a life cycle assessment carried out with the CAPRI model. Agric Ecosyst Environ 149:124-134. https://doi.org/10. 1016/j.agee.2011.12.015

Publisher's Note Springer Nature remains neutral with regard to jurisdictional claims in published maps and institutional affiliations. 